\title{
CHRONIC INTERACTION BETWEEN METFORMIN AND MELOXICAM IN MICE
}

\author{
FALAH MUOSA KADHIM AL-REKABI*
}

Department of Physiology, Biochemistry and Pharmacology College of Veterinary Medicine, University of Baghdad, Iraq. Email: fab20062003@yahoo.com

Received: 25 September 2018, Revised and Accepted: 17 November 2018

ABSTRACT

Objective: This study is performed for investigation the chronic interaction between metformin and meloxicam from toxicological view.

Methods: Lethal dose 50 after chronic exposure assessed in mice by up and down method. Their interaction analyzed by isobolographic analysis indicated that both medicines exhibited synergism. Assessment of the effects of repeated chronic dosing for 3 months of both medicines also performed on mice. Medicines in question administered orally as therapeutic doses of metformin $14 \mathrm{mg} / \mathrm{kg}$. Body weight (BW) (G) meloxicam $0.2 \mathrm{mg} / \mathrm{kg}$.BW $\left(G_{2}\right)$, and combination of both medicines $\left(G_{3}\right)$ while $G_{4}$ assigned control and dosed DW.

Results: Both $\mathrm{G}_{1}$ and $\mathrm{G}_{3}$ showed significant $\mathrm{p}<0.05$ decrease in blood glucose and serum cholesterol levels. Meloxicam group $\left(\mathrm{G}_{3}\right.$ ) showed statistically significant $p<0.05$ increase in triglycerides and alanine aminotransferase (ALT), and aspartate aminotransferase (AST), while group of combination showed statistically significant $\mathrm{p} \leq 0.05$ decrease in both ALT and AST. Blood urea nitrogen, uric acid, and serum creatinine showed statistically significant $p<0.05$ increase in group of meloxicam but decrease in $G_{3}$ and no changes in $G_{1}$. Histopathological changes included variable lesions in kidney such as swelling and necrosis in renal tubules of metformin group, cortical vacuolar degeneration in renal tubules, and deterioration of most glomeruli in $G_{2}$, while $G_{3}$ showed generalized cortical necrosis of renal tubules and interstitial nephritis. Liver lesions included central venous congestion (VC) and perivascular lymphocytic infiltration and marked necrosis in both groups of metformin and meloxicam, while there were severe $\mathrm{VC}$ and necrosis of hepatocytes in group of combination.

Conclusion: Metformin administration with meloxicam may have beneficial important through preventing many deleterious effects of meloxicam after long-standing administration, but adjusting dosing regimen study might be recommended.

Keywords: Chronic, Interaction, Metformin, Meloxicam, Mice.

(C) 2019 The Authors. Published by Innovare Academic Sciences Pvt Ltd. This is an open access article under the CC BY license (http://creativecommons. org/licenses/by/4. 0/) DOI: http://dx.doi.org/10.22159/ajpcr.2019.v12i2.29947

\section{INTRODUCTION}

More than 50 years, metformin is a worldwide prescribed antidiabetic $[1,2]$, it is a biguanide derivative [3] and considered the cornerstone and first-line defense against type II diabetes mellitus (is a most common metabolic disorder) through decrease hepatic insulin resistance, decrease amyloid deposits, and alteration in bile acid metabolism [4,5]. The antihyperglycemic effect of metformin was dose dependent and ranged from maximum effect dose of 2000 to minimum $1000 \mathrm{mg} /$ day in most patients [6,7]. Metformin is primarily absorbed from the upper gastrointestinal tract [8]. The bioavailability of metformin is $50 \%$ [9]. It is delivered into liver in concentration more higher than in the blood, finely excreted unchanged through kidney $[10,11]$. Metformin alone is a relatively safe drug clinically with only mild side effects including gastrointestinal disturbances (diarrhea, nausea, and irritation of the abdomen) [2]. Although the fact that the efficacy of metformin offers wide range of benefits beyond its blood glucose control, physicians have always been well aware of its adverse effects $[12,13]$. Meloxicam is a nonsteroidal anti-inflammatory (NSAID) has analgesic and antipyretic effects through the selective inhibition of cyclooxygenase-2 (COX-2) [14,15]. It is recommended for treating rheumatoid arthritis, osteoarthritis (OA), postoperative pain and fever [16]. Meloxicam recommended at dose $15 \mathrm{mg} /$ day in the treatment of rheumatoid arthritis [17], its bioavailability in mice is $94 \%$ after oral administration [18]. Meloxicam administration can result some gastrointestinal side effects such as intestinal bleeding and also serious cardiovascular problem, especially in persons are suffering from hypertension, hypercholesterolemia, and diabetes [19]. Liver and kidney toxicity both are adverse effects of meloxicam [20]. Prolonged uses of NSAIDs can produce severe adverse effects [21]. The ability of metformin to decrease pain severity and inflammation in that contributed to the pathophysiology of OA, with no serious adverse effects, has been carried out in many animal model studies [22,23]. This can be indicated that metformin can be recommended as potential drug to treat inflammation-related disorders [22]. Several studies have demonstrated that inflammation correlates with incident diabetes [24]. The expression of COX-2 is increased in the peripheral tissues of diabetic neuropathy models [25]. NSAIDs are a double-edged sword in that their long-term use requires caution due to their well-known side effects [26,27]. Extensive studies are required to validate the safety and evaluation of some toxicological aspects of coadministration of metformin and meloxicam, so we are targeted one aspect which is represented by chronic interaction between these two medicines in mice.

\section{METHODS}

\section{Medicines and chemicals}

Mobic ${ }^{\circledR}$ tablet contains $15 \mathrm{mg}$ meloxicam obtained from Boehringer Ingelheim (Germany) and Glucophage ${ }^{\circledR}$ film-coated tablet contains $500 \mathrm{mg}$ metformin from MERECK SERONO (France). Commercial Kits from Biosystems (Spain) used for the assessment of random blood glucose, cholesterol, triglycerides (TGs), alanine aminotransferase (ALT), aspartate aminotransferase (AST), blood urea nitrogen (BUN), serum creatinine, and serum uric acid.

\section{Animals}

Balb-C male mice, 3 months ago, purchased from Pharmaceutical quality control/Ministry of Health - Iraq. They were housed under optimum condition of temperature $25 \pm 1^{\circ} \mathrm{C}$ with photoperiod followed dark: light cycle of 12:12 h along the period of experiment. Standard rodent pellet feed and drinking water provided ad libitum. They were remaining 2 weeks for acclimatization before any interference. 
Experimental design

This experiment was carried out as approved by the Scientific Committee in Physiology, Biochemistry, and Pharmacology Department/College of Veterinary Medicine, University of Baghdad, accordance to ethical standard of working on laboratory animals.

\section{Dosages and dosing}

All medicines that involved were calculated according to the body weight (BW) of animal as $\mathrm{mg} / \mathrm{kg}$.BW. They were administered with dose volume $0.1 \mathrm{ml} / 10 \mathrm{~g}$.BW of mice by calculating and fitting all their concentrations for all experiments.

\section{Median lethal dose $50\left(\mathrm{LD}_{50}\right)$ assessment}

Median $\mathrm{LD}_{50}$ of meloxicam, metformin, and their combination had calculated after chronic orally administration by up and down method [28]. Regarding to the outcome of each dose whether the animal was dead or alive, the doses of both medicines were decreased and increased by $20 \%$ respectively. $\mathrm{LD}_{50}$ for each medicine and their combination was calculated by the following equation:

$\mathrm{LD}_{50}=\mathrm{XF}+\mathrm{Kd}$

Where, $\mathrm{Xf}=$ the last dose

$\mathrm{K}=$ Constant

$\mathrm{d}=$ difference between doses.

Assessment of interaction of both medicines (isobolographic analysis)

The isobolography analysis used to determine the sort of interaction between and meloxicam (drug A) and metformin (drug B), if we denote the intercepts by $A$ for the $\mathrm{LD}_{50}$ of drug $\mathrm{A}$ and by $\mathrm{B}$ for the $\mathrm{LD}_{50}$ of drug $\mathrm{B}$, then the isobole is expressed by the simple linear equation:

$$
\frac{\mathrm{a}}{\mathrm{A}}+\frac{\mathrm{b}}{\mathrm{B}}
$$

Where, $a$ is the $\mathrm{LD}_{50}$ of drug $\mathrm{A}$ and $\mathrm{b}$ is of drug $\mathrm{B}$ when the two are administered together and the $A$ and $B$ are now the respective individual doses. The isobole expressed in equation above allows the assessment of the interactions whether are synergism, antagonism, or additive when actual combination doses are tested. If testing shows that the specified effect of a combination is achieved by a dose pair that plots as a point below the isobole, this means that the effect was attained with doses less than those on the line, a situation that denotes synergism. In contrast, an experiment may show that greater combination doses are needed to produce the specified effect, and therefore, this dose pair plots as a point above the isobole line denote antagonism. Dose pairs that experimentally lie on the line (or not significantly off the line) are termed additive [29].

\section{Assessment of the effects of repeated chronic dosing of both} medicines

A total of 20 male Balb-C mice divided equally into four groups, orally administered all medicines daily for 3 months and assigned as Group 1 $\left(\mathrm{G}_{1}\right)$ metformin $14 \mathrm{mg} / \mathrm{kg} . \mathrm{BW}$, Group $2\left(\mathrm{G}_{2}\right)$ meloxicam $0.2 \mathrm{mg} / \mathrm{kg} . \mathrm{BW}$, and Group $3\left(\mathrm{G}_{3}\right)$ combination of metformin plus meloxicam while the $4^{\text {th }}$ group (C) dosed distilled water and considered control group.

Blood samples collected after 3 months of dosing through heart puncture technique, serum obtained by centrifugation with $3000 \mathrm{rpm}$ for $10 \mathrm{~min}$ for clinical chemistry. Blood glucose by spectrophotometry measured coupled colored complex quinoneimine [30]. Serum Cholesterol was measured by spectrophotometric method, briefly by converting cholesteryl ester to cholestenone [31]. TGs measured spectrophotometrically by converting them to glycerol [32]. AST estimated spectrophotometry through determination catalytic concentration of enzyme from the rate of decreased nicotinamide adenine dinucleotide [33]. Serum uric acid measured through coupled reaction which converts uric acid to allantoin in the presence of uricase and colored complex that can be measured by spectrophotometer $[34,35]$. BUN measured spectrophotometrically through coupled reaction which mediated by urease and glutamate dehydrogenase to form glutamate and NAD which could be measured [36,37]. Serum creatinine measured by reaction with picric acid in alkaline medium and forming colored complex which could be measured spectrophotometrically $[38,39]$.

Statistical analysis was carried out by SPSS version 24.00. One- and two-way ANOVA employed to differentiate between means. $p<0.05$ was considered statistically significant. Least significant differences (LSD) used to compare between means.

\section{RESULTS}

Median $\mathbf{L D}_{50}$

The results of median $\mathrm{LD}_{50}$ of metformin, meloxicam alone, and their combination after chronic repeated administration in male mice are summarized in Table 1. Regarding to isobolography of two medicines metformin and meloxicam, simultaneously administrated in combination exhibited synergism with value of 0.77 (Diagram 1). Clinical observation of all mice subjected to both exposures for $24 \mathrm{~h}$ revealed restlessness or anxiety, raised tail, and grooming included rapid respiration, tremor, convulsions, laying down on one side, and finally death along $24 \mathrm{~h}$ of administration.

\section{Clinical chemistry}

\section{Blood glucose, serum cholesterol, and TG}

The both Groups 1 (metformin) and 3 (metformin+meloxicam) revealed statistically significant $p<0.05$ decrease in blood glucose level while Group 2 (meloxicam), showed non-significant change, in comparison with control group, Table 2. The serum cholesterol level of both Groups 1 and 3 showed statistically significant $p<0.05$ decrease while

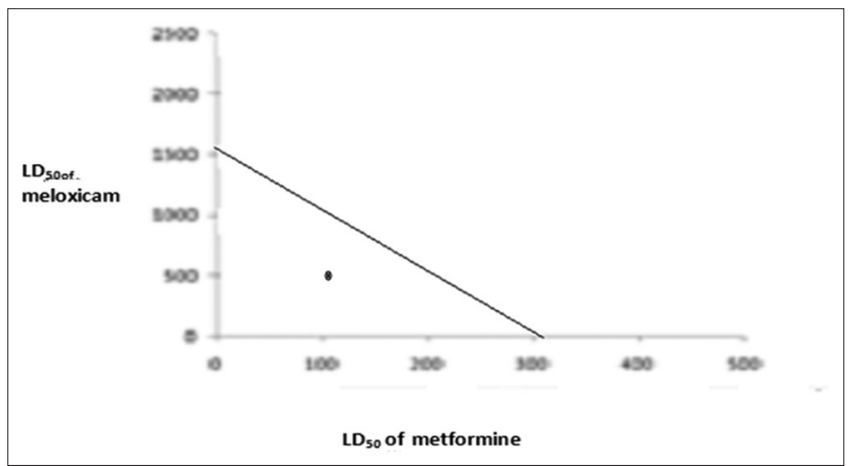

Diagram 1: Isobolographic of combination lethal dose 50 of metformin plus meloxicam in mice after orally chronic administration

Table 1: $\mathrm{LD}_{50}$ of metformin, meloxicam, and their combination after chronic orally administration in male Balb-C mice

\begin{tabular}{|c|c|c|c|c|c|c|}
\hline Medicine & Initial dose mg/kg.BW & Last dos mg/kg.BW & Number of animals & Outcome & Differences between doses & $\mathrm{LD}_{50} \mathrm{mg} / \mathrm{kg} . \mathrm{BW}$ \\
\hline Metformin & 1000 & 1400 & 5 & OXOOX & 200 & 1575.6 \\
\hline Meloxicam & 400 & 240 & 5 & OXXXO & 80 & 303 \\
\hline Metf+melox & $755.5+171.5$ & $755.5+171.5$ & 5 & XOXOX & 200 metf, 80 melox & $615.3+115.42$ \\
\hline
\end{tabular}

$\mathrm{K}$ of metformin $=0.878$, K of meloxicam $=1.288$, K of combination $=-0.701 . \mathrm{LD}_{50}$ : Lethal dose 50 , BW: Body weight 
Table 2: Glucose mg/dl, cholesterol mg/dl, and TG mg/dl

\begin{tabular}{lll}
\hline Group & Glucose $\mathbf{M} \pm$ SE & Cholesterol M \pm SE \\
\hline$G_{1}$ (metformin) & $49.00 \pm 4.99 \mathrm{C}$ & TG M \pm SE \\
$G_{2}$ (meloxicam) & $141.60 \pm 4.26 \mathrm{~A}$ & $76.00 \pm 1.81 \mathrm{~B}$ \\
$\mathrm{G}_{3}$ (metformin+meloxicam) & $105.00 \pm 2.73 \mathrm{~B}$ & $75.60 \pm 1.96 \mathrm{~A}$ \\
$\mathrm{G}_{4}$ (DW) control & $144.60 \pm 3.04 \mathrm{~A}$ & $46.40 \pm 3.90 \mathrm{~B}$ \\
LSD & 9.23 & $94.60 \pm 19.04 \mathrm{~A}$ \\
\hline
\end{tabular}

Capital letters denote statistically significant differences $\mathrm{p}<0.05$ between groups. LSD: Least significant differences

Group 2 did not show any significant change in comparison with the control group, Table 2. The only serum TG level of Group 2 (meloxicam) exhibited statistically significant $\mathrm{p}<0.05$ increase, while other treated Groups 1 and 2 did not do when compared to control group, Table 2.

\section{ALT and AST}

The animals of treated group two (meloxicam) showed statistically significant $\mathrm{p}<0.05$ increase in both ALT and AST serum activity in comparison with both treated Groups 1 and 3 (metformin, combination) and control group. Furthermore, Group 3 revealed statistically significant $p<0.05$ increase in both ALT and AST when compared to $G_{1}$ and control group, while Group 1 did not show any significant changes in both enzymes activity in comparison with the control, Table 3.

\section{Serum uric acid, creatinine, and BUN}

The animals of Group 2 (meloxicam) revealed statistically significant $\mathrm{p}<0.05$ increase in serum uric acid, creatinine, and BUN when compared to other treated groups and control, while the animals of Group 1 (metformin) showed non-significant changes in all these parameters in comparison with the control one. Group 3 (combination) showed statistically significant $\mathrm{p}<0.05$ decrease in uric acid, increase in serum creatinine in comparison to the control group, and there is no significant change in BUN, Table 4.

\section{$B W$}

There were statistically significant $\mathrm{p}<0.05$ differences in $\mathrm{BW}$ between all treated groups before treatment while after 3 months, the BWs revealed no significant differences. However, the results of BW within groups showed statistically significant $p<0.05$ decrease after 3 months of treatment in comparison with their pretreatment BWs, Table 5.

\section{Histopathology}

\section{Kidney}

The renal sections of $G_{1}$ (metformin) showed acute generalize cortical cellular swelling with necrosis of renal tubules, and medullary vacuolar degeneration (Vd) and necrosis of tubules (Figs. 1 and 2). The renal histopathological lesions of $G_{2}$ (meloxicam) were included severe cortical Vd of proximal and distal renal tubules with deterioration of most glomeruli (Fig. 3); however, the renal medulla showed variable degrees of degenerative changes of collecting tubules with cast formation and necrosis (Fig. 4), while $\mathrm{G}_{3}$ (metformin plus meloxicam) revealed generalize cortical necrosis of renal tubules and acute cellular swelling and interstitial nephritis in medulla (Fig. 5).

\section{Liver}

Liver section of both $\mathrm{G}_{1}$ and $\mathrm{G}_{2}$ showed similar histopathological lesions which represented by central venous congestion (VC), perivascular lymphocytic infiltration with marked necrosis of hepatocyte cords (Fig. 6). The lesion which was observed in liver of $G_{3}$ included severe central VC, disarranged of hepatocyte cords, and necrosis (Figs.7 and 8).

\section{DISCUSSION}

Drug interaction is a status when two or more than one medicine are taking simultaneously for caring certain disease. Mostly, in clinical application, physicians prescribe more than one medicine, so these medicines may interfere between each other through
Table 3: ALT and AST (U/L)

\begin{tabular}{lll}
\hline Group & ALT M \pm SE & AST $\mathbf{M} \pm$ SE \\
\hline $\mathrm{G}_{1}$ (metformin) & $38.60 \pm 3.48 \mathrm{C}$ & $94.60 \pm 4.54 \mathrm{C}$ \\
$\mathrm{G}_{2}$ (meloxicam) & $88.00 \pm 4.27 \mathrm{~A}$ & $167.80 \pm 9.02 \mathrm{~A}$ \\
$\mathrm{G}_{3}$ (metformin+meloxicam) & $57.00 \pm 8.22 \mathrm{~B}$ & $129.64 \pm 10.02 \mathrm{~B}$ \\
$\mathrm{G}_{4}$ (DW) control & $34.20 \pm 3.73 \mathrm{C}$ & $100.20 \pm 7.67 \mathrm{C}$ \\
LSD & 13.06 & 19.97 \\
\hline
\end{tabular}

Capital letters denote statistically significant differences $\mathrm{p}<0.05$ between groups. ALT: Alanine aminotransferase, AST: Aspartate aminotransferase. LSD: Least significant differences

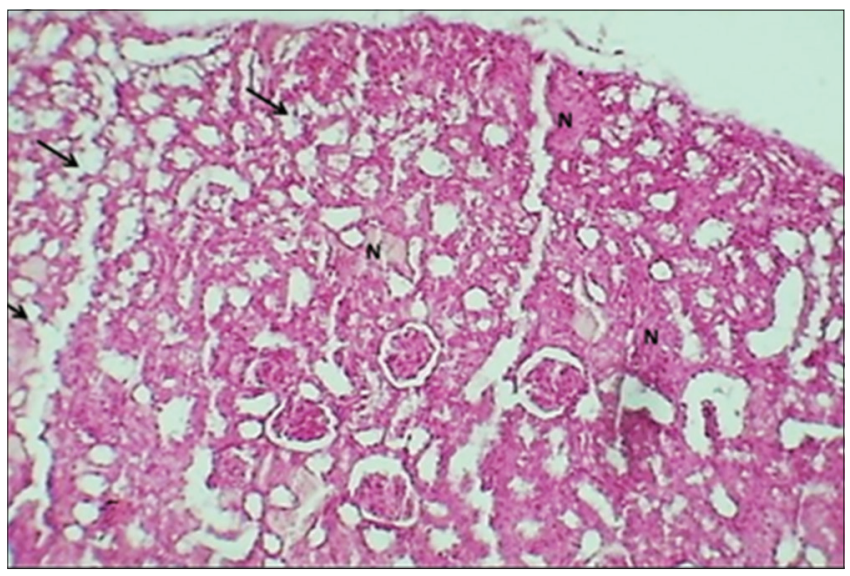

Fig. 1: Section of renal cortex $\left(G_{1}\right)$ shows cellular swelling (arrows) and necrosis of renal tubules $(\mathrm{N})$. Hematoxylin and eosin stain $\times 100$

pharmacokinetic pathways or pharmacodynamically. Both pharmacological pathways consequence several sorts of interactions whether are beneficial or non-beneficial. The beneficial one is mostly therapeutically desirable while the non-beneficial one may be considered toxicological interaction and may harmful to the patient. Here, we conducted our study to review the interaction between hypoglycemic medicine metformin and analgesic, anti-inflammatory one meloxicam from some toxicological views, which included evaluation chronic interaction trough measuring $\mathrm{LD}_{50}$ of both two medicines when administrated separately and in combination, also some liver and kidney functions biochemical markers use as tools for this purpose. In such study, in mice, both medicines showed synergism and antagonism sort of interaction after acute and subchronic administration, respectively [40].

We thought the decrease in blood glucose level in the animals treated with metformin alone and in combination is a logical consequence due to hypoglycemic effect of metformin, meloxicam did not influence the hypoglycemic effect of metformin, and this is also evident by not affecting the level of blood glucose level in the mice that treated with meloxicam alone. It is noteworthy that the remaining $50 \%$ of metformin, which is unabsorbed, accumulates in the gut mucosa of the distal small intestine at concentrations 30-300-fold greater than in the plasma [41]. Moreover, ultimately is eliminated with feces. However, in humans, gut effect of metformin remains largely obscure, although several 
Table 4: Uric acid, creatinine, and BUN

\begin{tabular}{|c|c|c|c|}
\hline \multirow[t]{2}{*}{ Group } & Uric acid & Creatinine & BUN \\
\hline & $\mathrm{M} \pm \mathrm{SE}$ & $\mathrm{M} \pm \mathrm{SE}$ & $\mathrm{M} \pm \mathrm{SE}$ \\
\hline $\mathrm{G}_{1}$ (metformin) & $6.30 \pm 0.43 \mathrm{BC}$ & $0.42 \pm 0.03 \mathrm{C}$ & $23.00 \pm 3.27 \mathrm{~B}$ \\
\hline $\mathrm{G}_{2}$ (Meloxicam) & $14.80 \pm 1.71 \mathrm{~A}$ & $1.64 \pm 0.15 \mathrm{~A}$ & $40.40 \pm 3.31 \mathrm{~A}$ \\
\hline $\mathrm{G}_{3}$ (metformin+meloxicam) & $5.28 \pm 0.28 \mathrm{C}$ & $1.00 \pm 0.27 \mathrm{~B}$ & $23.60 \pm 2.11 \mathrm{~B}$ \\
\hline $\mathrm{G}_{4}^{3}(\mathrm{DW})$ control & $9.82 \pm 2.50 \mathrm{~B}$ & $0.34 \pm 0.05 \mathrm{C}$ & $24.80 \pm 1.49 \mathrm{~B}$ \\
\hline LSD & 3.8 & 0.13 & 6.57 \\
\hline
\end{tabular}

Capital letters denote statistically significant differences $\mathrm{p}<0.05$ between groups. LSD: Least significant differences, BUN: Blood urea nitrogen

Table 5: BW/kg

\begin{tabular}{lll}
\hline Group & Pretreatment M \pm SE & After $\mathbf{3}$ months of treatment M \pm SE \\
\hline $\mathrm{G}_{1}$ (metformin) & $27.05 \pm 1.26 \mathrm{~B} \mathrm{a}$ & $23.33 \pm 0.84 \mathrm{~A} \mathrm{~b}$ \\
$\mathrm{G}_{2}$ (meloxicam) & $29.25 \pm 0.94 \mathrm{~B} \mathrm{a}$ & $23.33 \pm 0.98 \mathrm{~A} \mathrm{~b}$ \\
$\mathrm{G}_{3}$ (metformin+meloxicam) & $32.50 \pm 6.44 \mathrm{~A} \mathrm{a}$ & $23.66 \pm 0.95 \mathrm{~A} \mathrm{~b}$ \\
\hline
\end{tabular}

$L S D=2.48$. Capital letters denote statistically significant differencesp $<0.05$ between groups. Small letters denote statistically significant differences $p<0.05$ within groups. LSD: Least significant differences, BW: Body weight

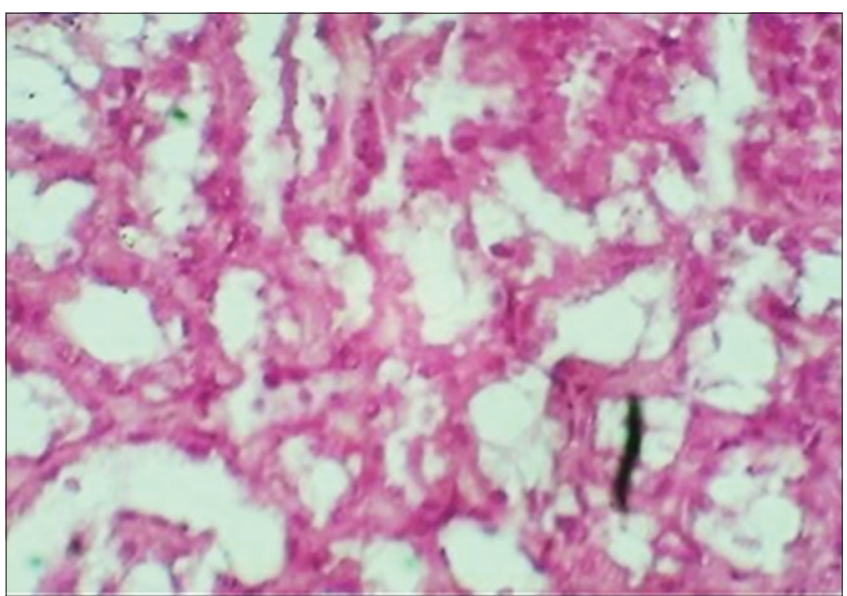

Fig. 2: Section of renal medulla $\left(G_{1}\right)$ shows vacuolar degeneration and necrosis of tubules. Hematoxylin and eosin stain $\times 400$

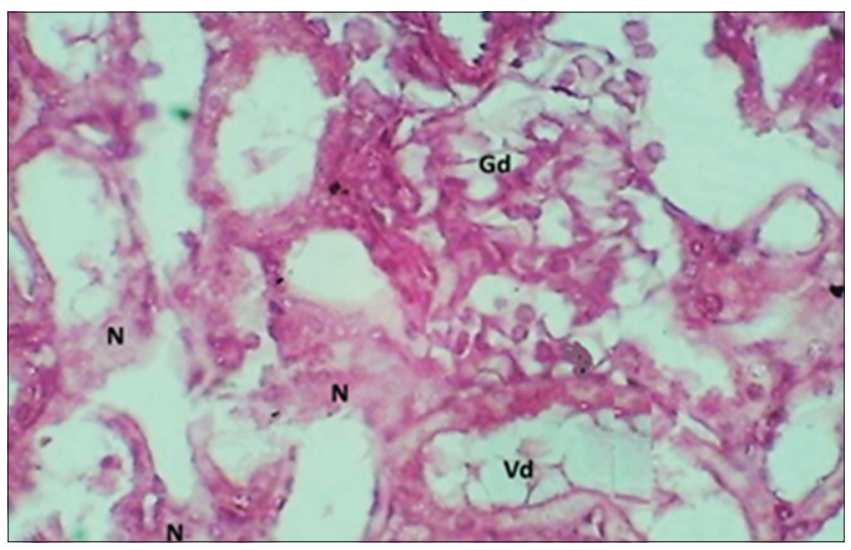

Fig. 3: Section of renal cortex $\left(G_{2}\right)$ shows vacuolar degeneration and necrosis of collecting tubules $(\mathrm{N})$. Hematoxylin and eosin stain $\times 400$

proposals have been suggested from animal experiments including delayed intestinal glucose absorption [2]. Metformin non-competitively inhibits the redox shuttle enzyme mitochondrial glycerophosphate dehydrogenase, resulting in an altered hepatocellular redox state, reduced conversion of lactate and glycerol to glucose, and decreased hepatic gluconeogenesis [42]. A certain study has demonstrated that the gut is the primary site of action [43].

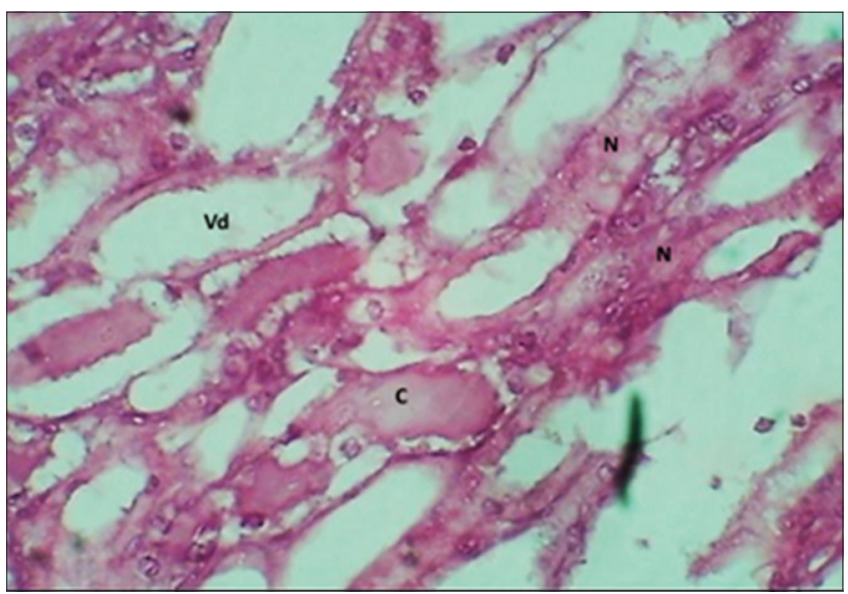

Fig. 4: Section of renal medulla $\left(\mathrm{G}_{2}\right)$ shows cast formation (C), vacuolar degeneration, and necrosis of collecting tubules $(\mathrm{N})$. Hematoxylin and eosin stain $\times 400$

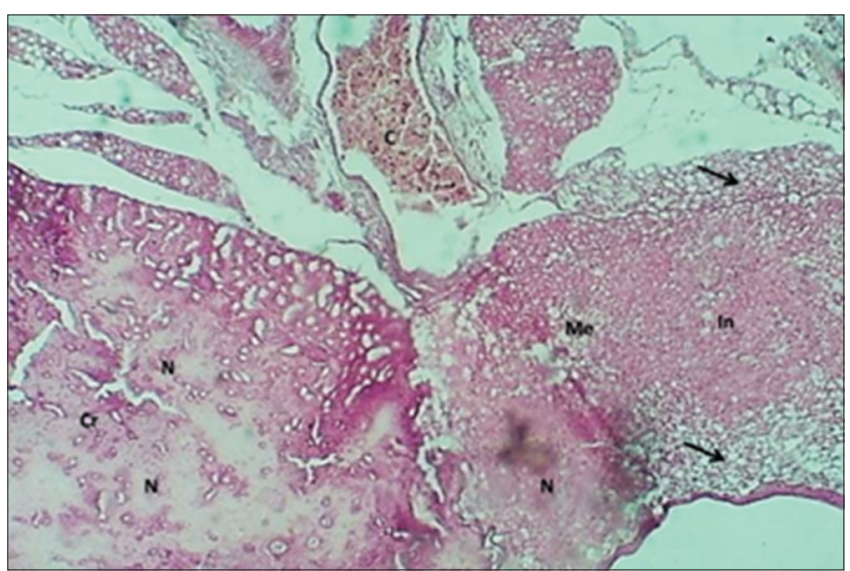

Fig. 5: Section of kidney $\left(\mathrm{G}_{3}\right)$ shows cortical region $(\mathrm{Cr})$, necrosis (N), medulla region (Me) interstitial nephritis (In), and acute cellular swelling (arrows). Hematoxylin and eosin stain $\times 400$

Hyperlipidemia is an elevation of lipids in the blood. These include cholesterol, cholesterol esters, phospholipids, and TGs [44]. Measurement of TG and total blood cholesterol is important in the diagnosis and management of hyperlipidemia, hypertriglyceridemia refers to high TG levels in the blood $[45,46]$. Acute pancreatitis is an 


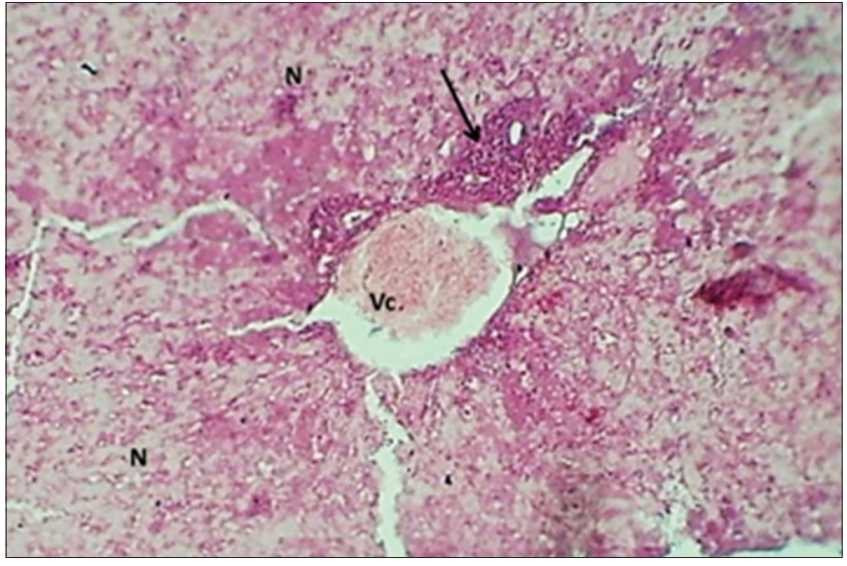

Fig. 6: Section of liver lobule shows, central venous congestion, lymphocytes infiltration (arrow), and necrosis (N). H and E stain $\times 400$

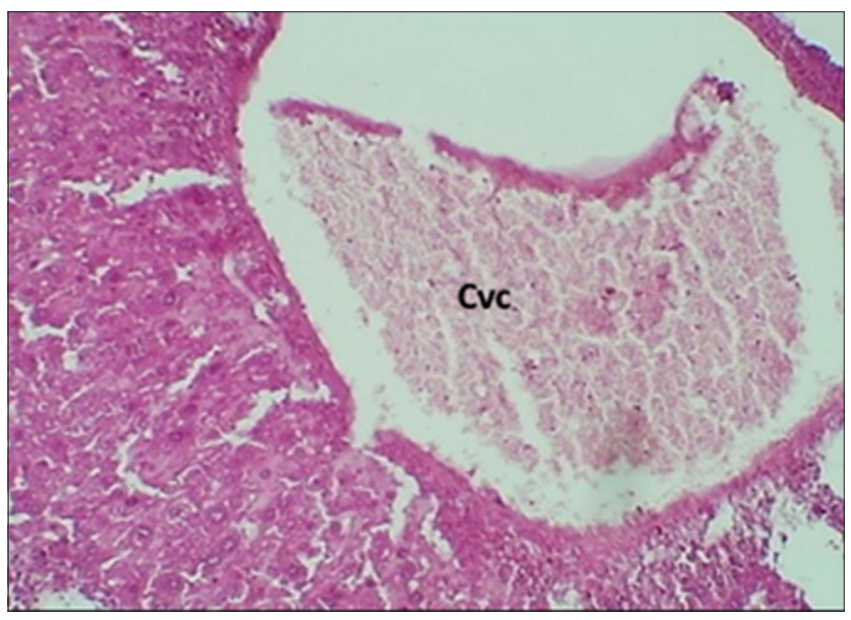

Fig. 7: Section of liver $\left(G_{3}\right)$ shows congestion of central vein (Cvc). Hematoxylin and eosin stain $\times \mathbf{1 0 0}$

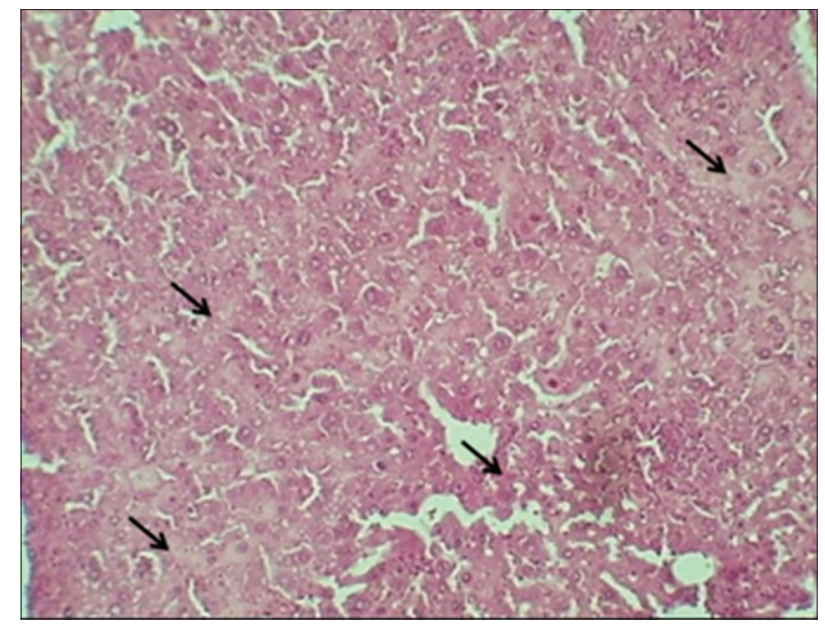

Fig. 8: Section of liver $\left(G_{3}\right)$ shows narcosis of hepatocytes (arrows) and marked disarrangement of hepatic hexagon. Hematoxylin and eosin stain $\times 100$

inflammatory process of the pancreas with varying involvement of other regional tissues or remote organ systems [47]. Very high TG levels also increase the risk of acute pancreatitis [48]. Chronic pancreatitis may develop as a result of acute pancreatitis, chronic pancreatitis can lead to diabetes or pancreatic cancer and unexplained weight loss may occur from a lack of pancreatic enzymes hindering digestion. We thought this is one of the relied perceptions of weight loss in mice of all experimental groups (Table 5), and the suspicion that meloxicam dosing is underlying in pancreatitis in mice especially of $\mathrm{G}_{2}$. However, up to $2 \%$ of acute pancreatitis cases may be caused by drugs $[49,50]$. Potential mechanisms of drug-induced pancreatitis include hypersensitivity (onset after 4-8 weeks of use), accumulation of a toxic metabolite (onset after several months of use), and hypertriglyceridemia (onset after several months of use) [47]. Meloxicam is one of the drugs which is implicated in $\leq 10$ cases of pancreatitis [49].

It has become increasingly apparent that the liver and kidney are also important targets for untoward clinical events of NSAIDs [51,52]. In general, the clinical manifestations of NSAID toxicity in liver can present as two distinct forms, mild hepatic changes and the more significant hepatic injuries. The mild hepatic changes, which are relatively frequent and usually observed in Phase III clinical trial before marketing, are evident as minor increases in liver enzymes in the plasma [53]. This is in agreement with our finding when we found mild increasing ALT activity in mice exposed to meloxicam for 3 months, Table 3; consequently, meloxicam caused mild hepatic change. However, orally administration both meloxicam and metformin to mice for 2 months had had no significant changes in serum TG, ALT, AST activity, and cholesterol [40]. On the other hand, the latter form of liver injury is rare but can have fatal outcome. In general, the mechanism is thought to be an idiosyncratic reaction (immunologic or metabolic) rather than an intrinsic toxicity of the agent. Although hepatotoxicity has been attributed to the entire therapeutic class of NSAIDs, the rates and types of injury often vary within and between chemical classes [54]. We thought that the mild hepatic histological lesion which represented by central VC, perivascular lymphocytic infiltration with necrosis of hepatocyte cords in $G_{3}$ mice (exposed to meloxicam) is not enough to being hepatotoxic. Generally, liver is highly regenerative organ which can overcome some injuries. One of the typical complications induced by COX-2 inhibitors was found, such as cardiovascular complications [54]. Somewhat, when we found increasing in AST activity in mice exposed to meloxicam only (Table 3), this is considered one of the several biomarkers referring cardiotoxicity. In a study by Al-Rekabi et al. [55], it was shown that administration of 0.2 and $0.6 \mathrm{mg} / \mathrm{kg}$ meloxicam to rats increased aspartate aminotransferase level.

COX-2 is also expressed constitutively in a few organs including the brain and kidney [56]. Basal levels of COX-2 have been located in the macula densa, thick ascending limbs, and papillary interstitial cells of rats and in the glomerular podocytes [57]. Despite extensive studies on the toxicity of NSAIDs on various organs, the mechanism of NSAID-induced renal injury has not been completely clarified said [53]. Obviously, the elevations in serum UA, creatinine, and BUN are clinically biomarker for renal impairment or toxicity; this is specifically proved in group received meloxicam only in our recent study, Table 4. Enzymatic substance determination in blood and sermi-optical test after Warburb. The thought that kidney susceptibility to any toxic injury is partially due to its high blood flow. Kidneys receive about 20$25 \%$ of the resting cardiac output, and hence, any drug in the systemic circulation will be delivered to this organ in relatively high amounts. The processes involved in forming concentrated urine also serve to concentrate potential toxicants in the tubular fluid [57]. In addition to the increase in the indices of renal toxicity due to the chronic exposure to meloxicam, there are also the severe histological changes observed in the kidneys of these mice, which were represented by severe cortical $\mathrm{Vd}$ of proximal and distal renal tubules with deterioration of most glomeruli. Since COX-2 is important in renal prostaglandin I2 synthesis, it implies that COX-2-selective inhibitors would have the same effects on renal function as conventional NSAIDs. Indeed, two COX-2-selective inhibitors, celecoxib and rofecoxib, have been shown to cause sodium retention and decrease glomerular filtration rate to a similar extent as non-selective NSAIDs [58]. 
Despite meloxicam is one COX-2-selective NSAIDs do not seem to spare the kidneys from adverse side effects. In a certain case report, a 56-yearold male who kept under metformin $750 \mathrm{mg}$ daily for long period, BUN, serum creatinine, and liver enzymes were in normal limit [59].

\section{CONCLUSION}

Metformin administration with meloxicam have may beneficial important through preventing many deleterious effects of meloxicam after long-standing administration, but adjusting dosing regimen study might be recommended.

\section{ACKNOWLEDGMENTS}

The author is very grateful to Prof. Dr. Duraid A Abbas for his scientific advice.

\section{AUTHOR'S CONTRIBUTIONS}

FMK Al-Rekabi designated the study and performed experiments as well analyzed the data.

\section{CONFLICTS OF INTEREST}

The author declares that they have no conflicts of interest.

\section{REFERENCES}

1. Bailey CJ, Day C. Metformin: Its botanical background. Pract Diabetes Int 2004;21:115-7.

2. Bailey CJ, Turner RC. Metformin. N Engl J Med 1996;334:574-9.

3. Kirpichnikov D, McFarlane SI, Sowers JR. Metformin: An update. Ann Intern Med 2002; 137:25-33.

4. Andújar-Plata P, Pi-Sunyer X, Laferrère B. Metformin effects revisited. Diabetes Res Clin Pract 2012;95:1-9.

5. Kala P, Jamuna RR, Kumar J. A comparative study of efficacy and safety among metformin with sitagliptin, metformin with voglibose, and metformin with glimepiride in patients with Type 2 diabetes mellitus. Asian J Pharm Clin Sci 2017;10:313-6.

6. Garber AJ, Duncan TG, Goodman AM, Mills DJ, Rohlf JL. Efficacy of metformin in Type II diabetes: Results of a double-blind, placebocontrolled, dose-response trial. Am J Med 1997;103:491-7.

7. Suzuki K, Yoshioka T, Wakui Y. Quantifying the effect of metformin $1000 \mathrm{mg}$ /day in Japanese patients with Type 2 diabetes. Int J Clin Med 2014;5:894-901.

8. Liesel C, Jonathan P, Vishwanath S, Sanman A, Sadhna J. Effect of food on the absorption of metformin from sustained release metformin hydrochloride formulations in healthy Indian volunteers. Asian J Pharm Clin Sci Res 2013;6:95-9.

9. Graham GG, Punt J, Arora M, Day RO, Doogue MP, Duong JK, et al. Clinical pharmacokinetics of metformin. Clin Pharmacokinet 2011;50:81-98.

10. Foretz M, Guigas B, Bertrand L, Pollak M, Viollet B. Metformin: From mechanisms of action to therapies. Cell Metab 2014;20:953-66.

11. He L, Wondisford FE. Metformin action: Concentrations matter. Cell Metab 2015;21:159-62.

12. Rojas LB, Gomes MB. Metformin: An old but still the best treatment for Type 2 diabetes. Diabetol Metab Syndr 2013;5:6.

13. Gionfriddo MR, Morey-Vargas O, Brito J, Leppin AL, Murad MH, Montori VM. Systematic reviews to ascertain the safety of diabetes medications topical collection on pharmacologic treatment of Type 2 diabetes. Curr Diabetes Rep 2014;14:478.

14. Dudhgaonkar SP, Tandan SK, BhatAS, Jadhav SH, Kumar D. Synergistic anti-inflammatory interaction between meloxicam and aminoguanidine hydrochloride in carrageenan-induced acute inflammation in rats. Life Sci 2006;78:1044-8.

15. Mahaprabhu R, Bhandarkar AG, Jangir BL, Rahangadale SP, Kurkure NV. Ameliorative effect of ocimum sanctum on meloxicam induced toxicity in wistar rats. Toxicol Int 2011;18:130-6.

16. Weyna DR, Cheney ML, Shan N, Hanna M, Zaworotko MJ, Sava V, et al. Improving solubility and pharmacokinetics of meloxicam via multiple-component crystal formation. Mol Pharm 2012;9:2094-102.

17. Huskisson E, Narjes H, Bluhmki E. Efficacy and tolerance of meloxicam, a new NSAID, in daily oral doses of 15,30 and $60 \mathrm{mg}$ in comparison to $20 \mathrm{mg}$ piroxicam in patients with rheumatoid arthritis. Scand J Rheumatol 1994;23:115.
18. Busch U, Schmid J, Heinzel G, Schmaus H, Baierl J, Huber C, et al. Pharmacokinetics of meloxicam in animals and the relevance to humans. Drug Metab Dispos 1998;26:576-84.

19. Stamm O, Latscha U, Janecek P, Campana A. Development of a special electrode for continuous subcutaneous $\mathrm{pH}$ measurement in the infant scalp. Am J Obstet Gynecol 1976;124:193-5.

20. Vane JR, Botting RM. Mechanism of action of aspirin-like drugs. Semin Arthritis Rheum 1997;26:2-10.

21. Mohammed M, Kassim J, Nizar A. Evaluation of the clinical use of metformin or pioglitazone in combination with meloxicam in patients with knee osteoarthritis; using knee injury and osteoarthritis outcome score. Iraqi J Pharm Sci 2017;23:13-23.

22. Kalariya NM, Shoeb M, Ansari NH, Srivastava SK, Ramana KV. Antidiabetic drug metformin suppresses endotoxin-induced uveitis in rats. Invest Ophthalmol Vis Sci 2012;53:3431-40.

23. Yuan H, Li L, Zheng W, Wan J, Ge P, Li H, et al. Antidiabetic drug metformin alleviates endotoxin-induced fulminant liver injury in mice. Int Immunopharmacol 2012;12:682-8.

24. Vozarova B, Weyer C, Lindsay RS, Pratley RE, Bogardus C, Tataranni PA, et al. High white blood cell count is associated with a worsening of insulin sensitivity and predicts the development of Type 2 diabetes. Diabetes 2002;51:455-61.

25. Goldfine AB, Fonseca V, Jablonski KA, Pyle L, Staten MA, Shoelson SE, et al. The effects of salsalate on glycemic control in patients with Type 2 diabetes: A randomized trial. Ann Intern Med 2010;152:346-57.

26. Agrawal NK, Kant S. Targeting inflammation in diabetes: Newer therapeutic options. World J Diabetes 2014;5:697-710.

27. Matsunaga A, Kawamoto M, Shiraishi S, Yasuda T, Kajiyama S, Kurita $\mathrm{S}$, et al. Intrathecally administered COX-2 but not COX-1 or COX-3 inhibitors attenuate streptozotocin-induced mechanical hyperalgesia in rats. Eur J Pharmacol 2007;554:12-7.

28. Dixon WJ. Efficient analysis of experimental observations. Annu Rev Pharmacol Toxicol 1980;20:441-62.

29. Tallarida RJ. Drug Synergism and Dose-effect Data Analysis. Boca Raton: CRC/Chapman-Hall; 2000.

30. Trinder P. Determination of glucose in blood using glucose oxidase with an alternative oxygen acceptor. Ann Clin Biochem 1969;6:24-7.

31. Allain CC, Poon LS, Chan CS, Richmond W, Fu PC. Enzymatic determination of total serum cholesterol. Clin Chem 1974;20:470-5.

32. Bucolo G, David H. Quantitative determination of serum triglycerides by the use of enzymes. Clin Chem 1973;19:476-82.

33. Gella FJ, Olivella T, Cruz Pastor M, Arenas J, Moreno R, Durban R, et al. A simple procedure for the routine determination of aspartate aminotransferase and alanine aminotransferase with pyridoxal phosphate. Clin Chim Acta 1985;153:241-7.

34. Barham D, Trinder P. An improved colour reagent for the determination of blood glucose by the oxidase system. Analyst 1972;97:142-5.

35. Fossati P, Prencipe L, Berti G. Use of 3,5-dichloro-2hydroxybenzenesulfonic acid/4-aminophenazone chromogenic system in direct enzymic assay of uric acid in serum and urine. Clin Chem 1980;26:227-31.

36. Talke H, Schubert G. Enzymatic substance determination in blood and sermi-optical test after Warburb. Clin Wkly 1965;43:174-5.

37. Gutman I, Bergmeyer HU. Methods of Enzymatic Analysis. $2^{\text {nd }}$ ed. New York: Academic Press; 1974.

38. Weber JA, van Zanten AP. Interferences in current methods for measurements of creatinine. Clin Chem 1991;37:695-700.

39. Peake M, Whiting M. Measurement of serum creatinine - current status and future goals. Clin Biochem Rev 2006;27:173-84.

40. AL-Rekabi FMK, Asker SJ, Shwaish MM. Acute and subchronic interaction between metformin and meloxicam in mice. J Pharm Tech 2018;11:2336-44.

41. Bailey CJ, Wilcock C, Scarpello JH. Metformin and the intestine. Diabetologia 2008;51:1552-3.

42. Madiraju AK, Erion DM, Rahimi Y, Zhang XM, Braddock DT, Albright RA, et al. Metformin suppresses gluconeogenesis by inhibiting mitochondrial glycerophosphate dehydrogenase. Nature 2014;510:542-6.

43. Buse JB, DeFronzo RA, Rosenstock J, Kim T, Burns C, Skare S, et al. The primary glucose-lowering effect of metformin resides in the gut, not the circulation: Results from short-term pharmacokinetic and 12week dose-ranging studies. Diabetes Care 2016;39:198-205

44. de Jongh S, Ose L, Szamosi T, Gagné C, Lambert M, Scott R, et al. Efficacy and safety of statin therapy in children with familial hypercholesterolemia: A randomized, double-blind, placebo-controlled trial with simvastatin. Circulation 2002;106:2231-7. 
45. Rubins HB. Triglycerides and coronary heart disease: Implications of recent clinical trials. J Cardiovasc Risk 2000;7:339-45.

46. Forrester JS. Triglycerides: Risk factor or fellow traveler? Curr Opin Cardiol 2001;16:261-4.

47. Tenner SS. Acute pancreatitis. In: Feldman M, Friedman L, Brandt L, editors. Sleisenger and Fordtran's Gastrointestinal and Liver Disease. $9^{\text {th }}$ ed.St. Louis, MO: Saunders; 2010.

48. Berglund L, Brunzell JD, Goldberg AC, Goldberg IJ, Sacks F, Murad MH, et al. Evaluation and treatment of hypertriglyceridemia: An endocrine society clinical practice guideline. J Clin Endocrinol Metab 2012;97:2969-89.

49. Trivedi CD, Pitchumoni CS. Drug-induced pancreatitis: An update. J Clin Gastroenterol 2005;39:709-16.

50. Nitsche CJ, Jamieson N, Lerch MM, Mayerle JV. Drug induced pancreatitis. Best Pract Res Clin Gastroenterol 2010;24:143-55.

51. Rostom A, Goldkind L, Laine L. Nonsteroidal anti-inflammatory drugs and hepatic toxicity: A systematic review of randomized controlled trials in arthritis patients. Clin Gastroenterol Hepatol 2005;3:489-98.

52. Murray MD, Brater DC. Renal toxicity of the nonsteroidal antiinflammatory drugs. Annu Rev Pharmacol Toxicol 1993;33:435-65.
53. Eng L. Action of Diclofenacand Meloxicam on Nephrotoxic Cell Death. Thesis (BSc. Hons). Singapore: National University of Singapore; 2008.

54. Hoshino T, Tabuchi K, Hara A. Effects of NSAIDs on the inner ear: Possible involvement in cochlear protection. Pharmaceuticals (Basel) 2010;3:1286-95

55. Al-Rekabi F, Abbas D, Hadi N. Effects of subchronic exposure to meloxicam on some hematological, biochemical and liver histopathological parameters in rats. Iraqi J Vet Sci 2009;23:249-54.

56. Vane JR, Bakhle YS, Botting RM. Cyclooxygenases 1 and 2. Annu Rev Pharmacol Toxicol 1998;38:97-120.

57. Khan KN, Venturini CM, Bunch RT, Brassard JA, Koki AT, Morris DL, et al. Interspecies differences in renal localization of cyclooxygenase isoforms: Implications in nonsteroidal antiinflammatory drug-related nephrotoxicity. Toxicol Pathol 1998;26:612-20.

58. Schnellmann R. Toxic responses of the kidney. In: Klaassen CD, editor. Casarett and Doull's Toxicology: The Basic Science of Poisons. New York, NY: McGraw-Hill; 2001. p. 583-608.

59. Yanto TA, Huang I, Kosasih FN, Lugito NPH. Nightmare and abnormal dreams: Rare side effects of metformin? Case Rep Endocrinol 2018;2018:7809305 